\title{
Getting and Keeping a Foot in the Door: Strategies by Migrant and Informal Sector Women to Remain Relevant in the Labour Market
}

\author{
Lillian Omondi ${ }^{1 *}$ Eva Maria Jernsand ${ }^{2} \quad$ Helena Kraff $^{3}$ \\ 1.Department of Sociology and Anthropology, Maseno University \\ Private Bag, Maseno, Kenya \\ 2. Department of Business Administration School of Business, Economics and Law, \\ University of Gothenburg, Sweden \\ 3. Academy of Design and Crafts - HDK - University of Gothenburg
}

This work was supported by Mistra Urban Futures

\section{Abstract}

United Nations Sustainable Development Goals (SDGs) 5 and 8 focus on gender equality; decent work and economic growth respectively. The achievement of these goals requires a realization that gender parity is significant to the growth of global economies, and that meaningful inclusion of women in the labour market is a major contributor to reducing the global gender gap. Over the years, there has been an increase in the participation of women in the labour market. Despite the various measures put in place, this inclusion continues to be hampered by structural and cultural factors. However stereotypic roles and responsibilities as well as systematic structural inequalities within the labour market continue to serve as barriers to optimal involvement and participation in gainful employment. This article seeks to explore these gender related inequalities that threaten to exacerbate women's economic vulnerability and dependence for specific localized groups of women in Kenya and Sweden. Using a framework based on structure, culture and agency, the article illuminates how these women navigate challenges presented by the nature of the job, multiplicity of roles and language as an empowering tool. Key insights from the study established that the women in the different contexts experienced similar threats and used their agency to maneuver these so as to participate as effectively as they could in the labour market. The coping mechanisms employed by these women present opportunities for policy makers and advisors in both contexts to explore in the quest to improve women's participation in the workforce.

Keywords: Gender, Labour Market, Migrants, Informal Sector, Social Networks, Agency.

DOI: $10.7176 /$ RHSS/9-22-02

Publication date: November $30^{\text {th }} 2019$

\section{Setting the Scene; An Introduction}

The number of women engaged in the global labour market continues to increase constantly. This improvement is however considerably slow with more than half of the $48 \%$ women of working age globally still unaccounted for (ILO, 2019). Literature also points to the fact that women are still in a disadvantaged position in the labour market (Moswete and Lacey, 2015). The nature and degree of involvement of women in the labour market varies between contexts, with poverty being the main driver in the global South, while higher educational achievements and availability of opportunities, provide an impetus for women's involvement in the global North (Verick, 2014). These push-pull factors tend to determine the conditions under which women work, their remuneration and subsequently their contribution to the household and national economy (Datta and Kotikula, 2018). Further, gender stereotypes about roles and responsibilities continue to see more women joining $61 \%$ of the global informal workers who consequently have no social protection (ILO, 2017). These stereotypes have also continued to confine women to 'pink-collar' jobs which in contemporary times has been used to describe jobs in the service industry (Hodson and Sullivan, 2012).

The global institution of the United Nations Sustainable Development Goals (SDGs), has reinforced the focus on the meaningful inclusion of women in the labour market. SDG 5 focuses on the achievement of gender equality and empowerment of all women and girls. Significant to this article is the recognition of this goal's targets that women's effective participation in the labour market is key to the achievement of equality and empowerment. SDG 5 also serves as important precursor to SDG 8 which seeks to ensure the delivery of decent work and economic growth (UN, 2015). This has consequently contributed to governments globally instilling measures to improve the participation of women in the labour force. Critical to note is that despite these measures, the global labour force continues to be lopsided with the representation of women lagging behind. In the low middle income countries for instance, females of working age form $33.7 \%$ of the labour force and there is still a significant difference between men and women's annual pay from a full-time position (ILO, 2018; Hegewisch and Hartmann, 2014). The proverbial "stuck between the sticky floor and the glass ceiling" (Lin and Morley, 2014) is explored in the article by acknowledging that even as SDG 5 aims at addressing some of the 
issues that still plague the process of engendering the workforce, there is recognition that certain structural arrangements within the labour market arena, that continue to impede women's participation in gainful employment. For instance, the wage gap and discrimination at the workplace being mentioned as some of the key issues.

The article builds on a comparison between two groups of women, who at face value have very little in common. The first a group of women in the process of entering the tourism labour market in Dunga community, Kisumu city in western Kenya. Dunga is an unplanned settlement that forms part of the informal belt surrounding the old town boundary. The inhabitants of this area are mainly in the informal sector of employment. The second a group of migrant women taking part of a labour market initiative aimed at the tourism labour market in West Sweden. This comparison may seem unjustified, since women's inclusion in the labour market generally looks remarkably different in the two countries, and they are often put in contrast with each other. The comparison is first and foremost based on Mistra Urban Futures' 'living laboratories' concept. This school of thought perceives the city as experimental area where new ideas and concepts are tried and tested within the framework of the 'triple helix' model (Etzkowitz and Leydesdorff, 1998). The living laboratories concept acknowledges the complexities surrounding urban processes of change and appreciates the interdependence of different sectors, disciplines and cultures (Polk, Kain and Holmberg, 2013). This was the idea behind the formation of five Local Interaction Platforms (LIPs) in Gothenburg, Malmo, Manchester, Kisumu and Cape Town. The processes towards the formation of these LIPs allowed for the setting of common guidelines in their 'modus oparendi' leading to sharing of trans-local perspectives on urban complexities (Perry, Patel, Bretzer and Polk, 2018). SKILLS (Sweden-Kenya Interactive Learning Labs), is a component of the project that seeks to enhance trans-local learning by exploring the comparative aspects of research findings that have taken place in these two interaction platforms since their collaboration began in 2012 .

Secondly and of further significance for the article was that both locations consisted of women who have migrated from their home to live in another place. In the Kenyan context, this consists of internal migration within the country as the women move to marry or join their spouses who have migrated in search of work, whilst in Sweden it is women who have come to Sweden from other countries as refugees. Both groups have thereby undergone changes in their social networks, which may affect their possibilities of successfully entering the labour market. Also, the constant migration of people across nations and continents results in countries having populations that are more and more culturally similar to each other. In this particular instance, migrants take some gendered notions of behavior with them from their home environment, whilst adopting new ones in their new country of residence thus increasing points of convergence.

\section{Within the Scope of Structure, Culture and Agency}

Having understood the contextual relationship, the authors considered the influence of structure, culture and agency in the participation of women in the labour market. They explored the works of both Giddens (1984) and Archer (1988). In explaining structuration, Giddens posits that "...conditions governing the continuity or transmutation of structures and therefore the reproduction of social systems". This in essence is what popularized Giddens theory, the fact that it acknowledges the existence of agents within a structure and that these agents are responsible for reproducing or changing the rules and resources within a system. According to Stone (2005), the notion of structuration is aimed at overcoming the objectivity and subjectivity of theoretical perspectives that tend to look at structure and agents as two separate entities - what Giddens calls 'dualism'. Structuration emphasizes the mutual relationship between structure and agents, without giving primacy to either. This is useful in explaining how human actions propagate or alter the systems within which they live. In relation to this article therefore, that would mean that how women chose to think or act would essentially influence how they were able to participate in the labour market and subsequently reinstate or transform the existing social systems regardless of their locale.

However, the structuration lens provides a very 'gender neutral' perspective, without taking into account how different cultures are 'gendered' and how these affect an individual's agency. Giddens opens up his theory for critique on this score when he questions if the separation of men and women is based on certain cultural attributes or general rules of stratification (Giddens, 2001). Yet in his structuration theory he goes ahead to treat culture as part of a wider social structure in its convergence with actors' agency. This presented an opportunity to explore the tenets of the morphogenetic perspective by Archer, (1995). This theoretical school of thought provides a platform for the consideration of structure and culture as autonomous yet mutually related concepts, while according each the requisite significance at any given time (ibid). Of particular interest to this perspective is how culture and structure penetrate the realms of the other. According to Archer, culture exerts its influence over the existing structure when the ideals of a dominant group infiltrate the system by asserting said ideals through different processes e.g. legislation. This, Archer says may of course have its benefits with regard to the adjustment of the structural domain, but not completely free of expense to the cultural system (ibid). If there is opposition to this emergent structure, an opposition group would subsequently use a set of cultural beliefs to 
counter the position of the dominant group. The effect of structure on culture Archer (1995), sees as more of an end product of this intersection. According to her, the acceptance or rejection of the ideals of this dominant group determine if there will be a 'new' way of life or if things go back to their original state. This morphogenesis of both structural and cultural aspects of society are therefore what influences actor agency. The article seeks to elucidate ways in which the women in both circumstances circumvent both structural and cultural obstacles by acting independently to regain power over situations that might otherwise deter their participation in the labour market and in the process possibly challenge existing narrative about their agency within the labour market realms.

\section{Methodology}

Qualitative methodology was used to collect data in both cases and a content analysis was done along emerging thematic areas. The Kenyan case made use of participatory methods for a focus group discussion conducted with 9 female tour guides referred to as Dunga Women in Tourism (DWiT). The Focus Group Discussion (FGD) made use of three participatory tools to elicit a discussion from the participants. The first tool that the participants interacted with was a force-field analysis. A forcefield analysis, developed by Kurt Lewin, (1951), provided the participants with a framework to discern factors that were either hampering or facilitating the execution of their duties as tour guides. This framework also explored coping strategies employed by these women as a way of managing the challenges experienced in the field of tour guiding.

Although poverty is not interchangeable with vulnerability, poverty measurements can be used to assess the economic vulnerability of a household (Moret, 2014). A wealth and vulnerability assessment was therefore conducted with the participants to establish if there were any changes within their households since their involvement in the tour guiding. The participants, using three big circles to denote a household, were asked to describe the characteristics of a poor, medium and rich household within their community. Using these as the measurement parameters, the participants were asked to place stickers representing their own households where they were at the beginning of the tour guiding engagement and where said households were currently. Finally, an access and control chart helped to establish the decision-making powers of men and women within their households. The purpose of this was to encourage social learning and provide insights into opportunities may exist for increasing women's access to and control of resources through their involvement in the labour market.

The Swedish example derives from a longitudinal action research project in which aims to explore the prerequisites and circumstances of newly arrived immigrant women's integration into the Swedish labour market. Focus was placed on the Swedish integration system in relation to a small social enterprise organising a programme for labour market introduction to the tourism industry, as well as on the participants and their experiences of the same programme. The participants learn about the tourism labour market, hospitality, service, product development and food security. As part of the programme, participants plan for and conduct food events where they come in direct contact with customers as part of introducing them to the labour market. One cycle of the programme lasts for four months, and has since the start in 2015 run nine times. Author two and three supported the social enterprise and the programme participants, for example, in the creation of and planning of food events. Observation notes were taken for a duration of two years as the authors observed the different programme activities. Qualitative and open ended interviews were held with six participants. Also, an ongoing dialogue were kept with the programme organisers, which were documented in the authors' respective research journals. One round of the programme had mainly female participants, which made the researchers note specific aspects of social inclusion and female labour market integration. These were set in relation to the earlier rounds of the programme when analysing the empirical material.

Emerging themes were identified, discussed and compared with the first author's findings, in her project in Kisumu. Together, all authors aligned their respective themes, according to situations, challenges and opportunities found in both cases. Three overarching thematic issues were identified and discussed from both contexts.

\section{Pink remuneration? An 'engendered' system of valuation}

Dunga Women in Tourism (DWiT), reported that most tourists often paid much less money than was paid to the male tourguides, and even this came across as tokenism rather than paying for a service received. The women felt that this may have been due the fact that they had not received much training and were therefore not very conversant with bird or plant species. Throughout the project however, it has been noted that whenever training sessions were held in the study area or requiring representation from this area, most attendees were usually men with the occasional 'symbolic woman' invited just to 'rubber stamp' the gender agenda. The gate keepers in this area were also men and this meant that they were the first point of contact for anyone conducting activities in Dunga - even the mobilization for the FGDs with the Women in tour guiding was done through these same male gate keepers. This aspect of gate keeping was also emphasized during the discussions when the female tour guides stated that the tourists mostly come into contact with the male counterparts who are able to negotiate 
better rates for themselves from the onset of the tour. Cultural hinderances also prevent women from operating boats and therefore DWiT could not take the tourists on boat rides to see hippos and the women felt that this may be another reason why their services are undervalued. However, it is important to note that each gender has components of the tour that were their forte. For instance, as part of the tour package tourists also get to experience lectures and tutorials about the different kinds of fish and the best way to prepare these as mealswhich is primarily done by the women. DWiT reported that as a way to circumvent this challenge, they sold cooked fish meals to guests who were willing to sample the local cuisine and had also organized themselves into a group that offers cultural dance performances to the guests as they arrive. This is especially done when large, organized groups of tourists are visiting the area. This enabled them to earn twice or thrice- from their group performance, from the sales of fish and then form other tour guiding activities. The women reported that this boosted their earnings and even though they still earned less than their male counterparts, it was slightly better than the initial situation. This was supported by the fact that the women felt that since they started the tour guiding activities, their earnings had contributed to improving the socioeconomic status of their households by enabling them increase their asset base and also provide better nutritional care for their families.

In the Swedish case the manager of the social enterprise mentions, in connection to a discussion on their food events, how women from countries such as Somalia are often asked to make samosas, but that the prize that customers are willing to pay is too low to make up for the time it takes to make them. It is a craft to assemble and cook samosas, although it is undervalued. This social enterprise connects to multicultural food events organized by a Swedish municipality where residents are invited to taste foods from a number of cultures. The events are popular and a large number of people come to taste foods from different countries like Syriah, Sweden and Somalia. One participant who prepared food for these events was now in the process of setting up a restaurant business with her family. This exemplifies the significance of these events as taking part in them can be seen as a way for people to improve their chances of engaging with the labour market. However, the fact that the food was free of charge, in similarity to the low priced samosas, risked the manifestation that these dishes were to be considered of low value, meaning that it would be difficult to charge decent prices in the future once businesses were established. This situation created a structure that could possibly bind actors to a disadvantageous situation. This provided insight into why food that is sold in countries such as Sweden, which are connected to certain cultures seemed to be placed in and stay in a lower price range and is often served as fast food. Whilst other types of food, for example that is connected to the Swedish West coast is viewed as fine dining, sold at higher prices. The focus on food events in the Swedish labour market integration programme was further seen as beneficial by participants, partly since it provided them with opportunities to talk Swedish with other Swedes in a natural environment. It also resulted in job opportunities for previous participants as they had been asked to partake in food events as hosts even after they have finished the programme. However, these were highly temporary opportunities which did not provide them with a full.

The aspect of 'engendered remuneration' in this empirical analysis may have resulted from several factors. First is the issue of socialization. Researchers have found that men's and women's average propensities to negotiate differ, with women being much less likely to do so (Babcock and Laschever 2003; Bertrand 2011; Croson and Gneezy 2009). Women's lower propensity to negotiate over salaries, raises, or promotions, could reduce their pay relative to men's. The observed gender difference could reflect social factors, including women being socialized to feel that they are being pushy or over-bearing (unfeminine) if they negotiate-i.e., pursuing their own goals in the face of conflict with others (Babcock and Laschever 2003). (Blau and Kahn, 2017).Men are also found to place a higher value on money, to have higher self-esteem, to be less risk averse, more competitive, self-confident and disagreeable, and to believe that they control their own fate (an internal, as opposed to external, locus of control) to a greater extent than women. Psychological attributes such as selfconfidence may contribute to a worker's productivity, and thus act like human-capital variables in a wage regression (Mueller and Plug 2006); Blau and Kahn, 2017).

Second is what Becker (1986), refers to as effective discrimination. Becker (1971) conceptualized discrimination as a taste and analyzed three cases: those in which the discriminatory tastes were held by employers, coworkers, and customers or clients. Under certain circumstances, such discrimination will cause a wage differential between men and women (Blau and Kahn, 2017). For instance, Moswete and Lacey, (2015) posit that, it was not the direct threat that is presented by men's involvement in the labour market that hinders the empowerment of women, but more the attitude held by said men about the capabilities of women to handle the requisite activities that came with the job to be done. This was in particular reference to tourism and business management. Similar to the preceding argument Spenceley \& Meyer, (2012); Landorf, (2009); Scheyvens, (2000), argues that tourism has seldom been considered as a poverty alleviation and empowerment tool for the poor and marginalized, especially women. This could have explained why the women in both instances earned little from their activities. Their clients may have actually seen it befitting to just offer a token of appreciation as opposed to actual payment for services delivered. 


\section{The morphogenesis of gendered time}

Role conflict leading to difficulties in time management was another issue that was identified by the participants of the study in both contexts. In Dunga for instance, the peak times for tourist activities is either early morning or late in the evening. DWiT however reported that this presented a challenge as in the morning they could not leave their household before their children and spouses had been prepared for school and work respectively. This involved making breakfast and ensuring they had all their necessities for the day. Further, since most of them were involved in the sale of fish as well, they had to ensure they had enough supply for the day prepped and ready for cooking or selling raw. In the evenings, they also could not go beyond four o'clock because they needed to pick up the children from school or ensure that they were home when the children got back or get back early to prepare dinner for the family. This was especially an issue for those with the younger kids. To enable them utilize their time effectively, the female guides utilized their networks in different ways. One is they would give the tourists they had engaged with their contacts and ask for a recommendation to other future tourists. When the tourists visited they would call them personally and if they are not able to attend to them they would recommend one of the other female guides. This they said was because they had realized that the guiding business relied a lot on 'word of mouth' marketing and if services rendered were good then the tourists would most likely mention it to their own networks. Two, they could use one of the other female guides to watch their wares if they needed to leave their fish station to attend to guiding duties. Three, they would ask a trusted neighbour or an older child to watch their children in the evening in case they needed to work an hour or two later at the beach unit. These measures they took they said, did not make them a hundred per cent efficient as their male counterparts still had more time to conduct tours, but they managed to increase the number of working hours which meant they were able to make a bit more money.

In Sweden, the programme for integration has been male dominated in terms of participants, with the exception of one cycle, where the majority were women. The daily programme ran up until 5 pm, which had not been an issue for participants most of the time. However, in the group with mainly women, many had to leave one to two hours early most days to collect their children from kindergarten or school. This gender difference was also visible during recruiting sessions for the programme, where women mentioned that they had children and wondered how they would manage the timings, an aspect that has not been brought up by male participants. Also, some of the foods event were held during weekends and some female participants mentioned that they could not participate since their husbands were working and they therefore needed to take care of the children. This despite the fact that the food events are seen the most important part of the programme by both participants and the programme organizers as it presents a good opportunity for participants to be in professional situations where they act in the organizations name, producing and selling their services. It also provides a good opportunity to practice Swedish as mentioned earlier. A participant, who had one child, expressed how important the support from her family, in particular that from her mother had enabled her attend the programme. She reported not having difficulties staying late in the afternoon since her mother picked her daughter up from kindergarten and prepared dinner before she got home.

Another aspect, affecting the women's possibilities to participate in activities for labour market integration was connected to the system and structures that are supposed to ease this integration. In Sweden, this is the national system of integration that newly arrived immigrants are supposed to attend. Participants in the programme are supposed to attend Swedish classes and civic orientation classes whilst also engaging in activities aimed to orient them towards the labour market. However, some of the women in the programme had missed class on numerous occasions since they were scheduled to attend their Swedish or civic orientation class at the same time as the scheduled labour market integration activities. This made it difficult for these participants who had erratic attendance to follow ongoing discourse in subsequent classes.

These structural as well as cultural hindrances are connected to the 'dual burden'(Odih, 1991) that women face when they are the main carer of the home whilst at the same time engaging in the labour market. It is structural in the sense that it relates to the fact that women globally still experience "work force interruptions" and "greater work-family conflicts" than men, resulting in a need to work shorter hours (Blau and Kahn, 2017). The fact that the women's possibilities to fully participate in the labour market is dependent on whether or not they are the ones responsible for collecting their children from school and taking care of household chores or whether there is someone else who can take that role, can be seen as both structural and cultural. This corresponds with previous research stating that newly arrived immigrants who do not have functional social networks or support structures, are particularly affected by the "motherhood penalty" (Adsera and Chiswick 2007; Banerjee and Phan, 2015). This also connects with the view in most cultures that women are still viewed as the main caretaker, whilst men are seen as the breadwinners (Stam, Verbakel, and de Graaf 2014; Ala-Mantila and Fleischmann, 2018). Furthermore, in feminist theories connections are made between women's labour market engagement and the notion of time. It is for example stated that there is a need to acknowledge the 'total social organization of time', which includes working hours, as well as household related work hours and leisure time (Glucksmann, 1998), and the power imbalances embedded in it (Negrey, 1993). One such imbalance is the 
'dual burden' (Odih, 1991) that women face when they are the main carer for the home and family, whilst at the same time engaging in the labour market (Owano, 2014). The primary socialization of young women into the roles of home- and child caring care is still highly influential in the balance between work and family. Men are often perceived as the main provider for the family and thus do not experience this form of role conflict to the same extent (Verbakel, and de Graaf 2014; Ala-Mantila and Fleischmann, 2018). Time is further also described as something that is distributed to individuals or groups, sometimes by someone else, and how this can produce unequal situations and disagreements regarding how it is managed (Glucksmann, 1998). Conflict may for example arise when an individual needs to attend to more than one work-related obligation at the same time (Glucksmann, 1998). Acknowledging these, and other time-related issues allows for reflections on how the organization of time may hinder women's possibilities for entering, or staying in the labour market in a successful manner.

\section{Language as a hindrance to labour market integration}

Communication is key in any service industry-even more so in tour guiding as the whole experience involves an articulate explanation of existing phenomena-both flora and fauna. This was however another of the challenges experienced by DWIT. Given that most of these women did not attend any formal training as tour guides, their language proficiency was not taken into account during recruitment as this was considered an 'informal' community run income generating activity. Some of the women are therefore not able to effectively communicate in English and this is a major hiccup when international tourists speaking neither Luo (the native language) nor Swahili, and forming the bulk of tourists needing guiding have to be taken on tours. The women found it difficult to explain some of the activities at the beach unit, particularly those known to them only in their native language. A noted example was explaining the process of getting and preparing the fish from the boats when they came in with the catch in the morning. Terms referring to the docking 'gowo' of the boats and scaling 'chwero' of fish for instance were problematic. In addition most of the women were very familiar with the names of flowers and trees found in the area but only in their native dialect as well. The utilization of social networks once again emerged as a main coping mechanism in this scenario. In cases where one tour guide had difficulties communicating in English, they formed a 'tag team' with another guide who could communicate better and shared the proceeds from the guiding activity.

Similarly in Sweden, language emerged as an obstacle for newly arrived immigrants who sought to penetrate the labour market. Being able to speak the Swedish language is further seen as key for successful integration into the society in general as it enables one to navigate the city fabric. For instance, they are able to know the bus schedules and routes, know what produce they are purchasing at the market etcetera. Immigrants who secure a resident permit are offered courses in Swedish. The design of these has however received critique. It is for example claimed that the heavy focus on writing assignments does not give people the possibility practice speaking Swedish, and using the words that they read and write in practice (Bucken-Knapp et al., 2018). This corresponded with participants reflections, who saw the programme as a good complement to their Swedish classes, since it provided a space where they got to practice Swedish verbally, and discuss words and phrases that deemed difficult. These possibilities to practice Swedish, were in other words seen by participants as taking them one step closer to the labour market. Language is considered a catalyst in labour market participation when one participant, who spoke both English and French believed that this would be beneficial when she applies for jobs in the restaurant industry, which is where her interests lie. A participant, mentioned how her children learned Swedish at pre-school, whilst she herself found it difficult to grasp the new language. However, this was seen as presenting an opportunity to make the learning of a new language easier. That is, the children, unconsciously, act as agents of change, affecting their parent's language skills in a positive way by talking to them in Swedish, or singing children's songs and watching children TV-shows in Swedish. This particular participant however also wanted to encourage the children to learn their mother-tongue as she wished to maintain and nourish it. This natural wish to maintain once mother-tongue and passing it on to your children can be seen as an internal hindrances making the learning of a new language difficult.

\section{Conclusion}

The purpose of this article is to elucidate ways in which women circumvent structural and cultural obstacles. Key insights from the study propose that the women, despite being in different cultural and geographical contexts, experience similar challenges and use their agency to maneuver these so as to gain access to or participate as effectively as they can in the labour market. The coping mechanisms employed by these women present opportunities for policy makers and advisors to explore in the quest to improve women's participation in the workforce. Further, regarding the analysis of the challenges for the two groups of women and their relation to the labour market, it was important for the authors of this paper to take into consideration how they represented the women through their writings, so as to not contribute to the reproduction of already simplified images of 'African' or 'refugee' women as vulnerable and exposed monolithic groups, without individual agency. 
The findings highlighted in this article provide policy makers and public organizations with impetus in enhancing efforts both aiming to heighten the perceived value and status of the work performed by women within and without the labour market. Critical questions arise and need to be addressed. How for instance is it possible to harness the role of social support and networks that supports women's engagement with the labour market? What strategies can be put in place to enhance these networks to ensure efficient and effective delivery for women who chose to venture into the world of work? Could it be about changing the perception that women are supposed to be the main carer of the family and how much readjustment of our social systems needs to be put in place to embrace women's role as contributors to the household and national economy? This article clearly illuminates that the empowerment of women to engage with the labour market is nuanced with aspects of agency that may enable actors in this field circumvent both structural and cultural barriers to women in the world of work. Therefore, as efforts are made to reduce structural and cultural constraints, even more efforts need to be geared towards strengthening the aspects of agency that may be a game changer in the field of women and work.

\section{References}

Adsera, A., \& Chiswick, B. R. (2007). Are there gender and country of origin differences in immigrant labor market outcomes across European destinations?. Journal of Population Economics, 20(3), 495.

Archer, M. (1995), Realist Social Theory. Cambridge University Press.

Archer, M., (1988). Realist Social Theory: the Morphogenetic Approach, Cambridge University Press.

Ala-Mantila, M., \& Fleischmann, F. (2018). Gender differences in labour market integration trajectories of recently arrived migrants in the Netherlands. Journal of Ethnic and Migration Studies, 44(11), 1818-1840.

Ali, S. (2007). Feminism and Postcolonial: Knowledge/Politics. Ethnic and Racial Studies,30(2), 191-212. doi: $10.1080 / 01419870601143877$

Banerjee, R., \& Phan, M. B. (2015). Do tied movers get tied down? The occupational displacement of dependent applicant immigrants in Canada. Journal of International Migration and Integration, 16(2), 333-353.

Blau, F D., and Kahn, L M. (2017). The Gender Wage Gap: Extent, Trends, and Explanations. Journal of Economic Literature, 55(3). Doi:789-865. https://doi.org/10.1257/jel.20160995.

Bucken-Knapp, G., Fakih, Z., and Spehar, A. (2018) Talking about Integration: The Voices of Syrian Refugees Taking Part in Introduction Programmes for Integration into Swedish Society. International Migration. Vol. 57 (2). pp. 221-234.

Datta, N., and Kotikula, A,. ( 2018). Not Just More, but Better - Fostering Quality of Employment for Women. Working Paper, World Bank.

Etzokowitz, H and Leydesdorff, L (1998). "The Endless Transition:A “Triple Helix" of University-IndustryGovernement Relations. Minerva 36(8), 203-208

Giddens, A. (2001). Sociology. $4^{\text {th }}$ Edition, Fully Revised and Updated. Cambridge, Oxford Polity

Giddens, A. (1994). Beyond Left and Right. The Future of Radical Politics. Stanford. Stanford University Press

Giddens, A., (1984)The Constitution of Society. Cambridge, Oxford Polity

Glucksmann, M. (1998). 'What a difference a day makes': A theoretical and historical exploration of temporality and gender. Sociology32(2), 239-258.

Harding, S. (1998). Is science multicultural?: postcolonialisms, feminisms, and epistemologies. Bloomington, Ind.: Indiana Univ. Press.

Hegeswisch, A and Hartman, H., (2014). Occupational Segregation and the Gender Wage Gap: A Job Half Done. Institute for Women's Policy Research.

Hodson, R., and Sullivan, T.A., (2012). The Social Organization of Work, Fifth Edition. USA, Wardworth

International Labour Organization (2019). Guide to Developing Balanced Working Time Arrangements. ISBN 978-92-2-133240-4

International Labour Organization (2018). World Employment and Social Outlook 2018. ISBN 9789221316473

International Labour Organization (2017).World Employment and Social Outlook 2017. ISBN 978-92-2$128882-4$

Mohanty, C T. (1988). Under Western Eyes: Feminist Scholarship and Colonial Discourses. Feminist Review30, 61-88.

Mohanty, C. T. (2003). "Under Western Eyes" Revisited: Feminist Solidarity through Anticapitalist Struggles. Signs, 28(2), 499-535.

Moswete, N., \& Lacey, G. (2015). "Women cannot lead": empowering women through cultural tourism in Botswana. Journal of Sustainable Tourism, 23(4), 600-617

Negrey, C. (1993).Gender, time, and reduced work. Albany, N.Y.: State University of New York Press.

Odih, P. (1991). Gendered time in the age of deconstruction. Time \& Society 8(1), 9-38.

Owano, N A. (2014). Gender disparities in Kenya. Journal of Research in Gender Studies 4(2), 298-312.

Perry, B., Patel, Z., Bretzer, Y. N., \& Polk, M. (2018). Organising for co-production: Local interaction platforms for urban sustainability. Politics and Governance,6(1),189-198. 
Polk M, Kain JH, Holmberg J (2013) Mistra Urban Futures: a living laboratory for urban transformations in regenerative sustainable development of universities and cities. In: Ariane König (ed) The role of living laboratories, Chapter 9. Edward Elgar Publishing, Cheltenham

Stam, K., Verbakel, E., \& de Graaf, P. M. (2014). Do values matter? The impact of work ethic and traditional gender role values on female labour market supply. Social indicators research, 116(2), 593-610

Lin, X., and Morley, G., (2014), Glass ceiling or sticky floor? Quantile regression decomposition of the gender pay gap in China, International Journal of Manpower, 35, 3, (306).

United Nations (2015), Transforming Our World: The 2030 Agenda for Sustainable Development. sustainabledevelopment.un.org

Verick, S., (2014). Female labor force participation in developing countries. IZA World of Labor 2014: 87 doi: 10.15185/izawol.87 